\title{
Laser Clot Blast Therapy for Central Retinal Venous Occlusion
}

\author{
Gurbax Singh* \\ International Eye Research and Cure Centre, India \\ *Corresponding author: Gurbax Singh, International Eye Research and Cure Centre, New Delhi, India
}

\begin{abstract}
Purpose: To report Yag laser clot blast therapy for central retinal venous occlusion.

Methods \& Materials: Prospective study of 10 patients. Best visual acuity was finger counting at 1 meter in all the cases, which were subjected to the treatment. The cases were followed up for 2-4 years (2.5 years).

Results: In 10 cases visual acuity improved to 0.4 (20/50) in 1st week treatment. The best final visual acuity improvement was $20 / 30$ in 8 and 20/40 in 2 cases.

Conclusions: Early Yag laser clotblast therapy is useful for rapid improvement of the visual acuity and prevents the complications secondary to central venous occlusion.

Most of the cases of the occlusion of central retinal vein invariably turned out to be unsuccessful with medical therapy given in the form of fibrinolytic agents, anticoagulants, hemodilution" and steroid4. The cases that present with Ischemic central retinal venous occlusion with visual acuity of 20/200 or less are typically unfavorable'. In most instances, even the laser photocoagulation does not yield a visual benefit compared with the natural course of the diseases. Surgical decompression of branch retinal vein occlusion via arteriovenous crossing sheathotomy has been tried successfully by some67' 8 to treat these cases but had led to complications associated with interventional vitrectomy including accelerated nuclear sclerotic cataract formation and retinal detachment. Others 9 have tried to develop chorioretinal anastomosis at the site of the venous block. However, others $1^{\circ}$ are trying to cannulise the blocked central retinal vein. As no single treatment for central retinal vein is yet successful, the authors tried a new modality of treatment in cases of central venous retinal occlusion.
\end{abstract}

\section{Methods and Materials}

The experimental procedure of Yag laser clot blast therapy was done in two blind eyes due to old optic atrophy after taking a written consent. There were no complications seen at time of laser application in the post laser follow up of 12 months. After this the present study was conducted at G.G.S.I.E Research \& Cure Centre from 1996 to 2001 after taking written consent of the patients. There were 10 cases of central retinal venous block of ischemic type. The ages of patients ranged from 24 to 70 years. In all the cases, best visual acuity was recorded with Snellen projector chart [1]. Charting of fields and ophthalmoscopic examination were done. The eyes were subjected to retinal fluorescein angiography. The patient was made to sit on a slit lamp. After insertion of mainster pan fundus contact lens, the Yag laser bursts of 1.0 milli Joules were started on the vein where it was entering as a branch or main trunk on the optic disc, the settings of the laser were kept at 125 micron anterior. If the energy released was less, it was increased to 2 to 3 milli Joules. After giving 4 bursts at the disc, a total of 6-12 bursts were given along the entire length of the blocked vein and venules till the 2nd A.V. crossing (Figure1). The patients were sent back and were asked to report once in a week till 4th week and then fortnightly till a follow up of 2-4 yrs (2.5yrs) [2]. A complete examination of the eye including recording of best visual acuity, field charting, intra-ocular pressure, slit lamp, ophthalmoscopic examination and fluorescein angiography was done during the follow up period. 


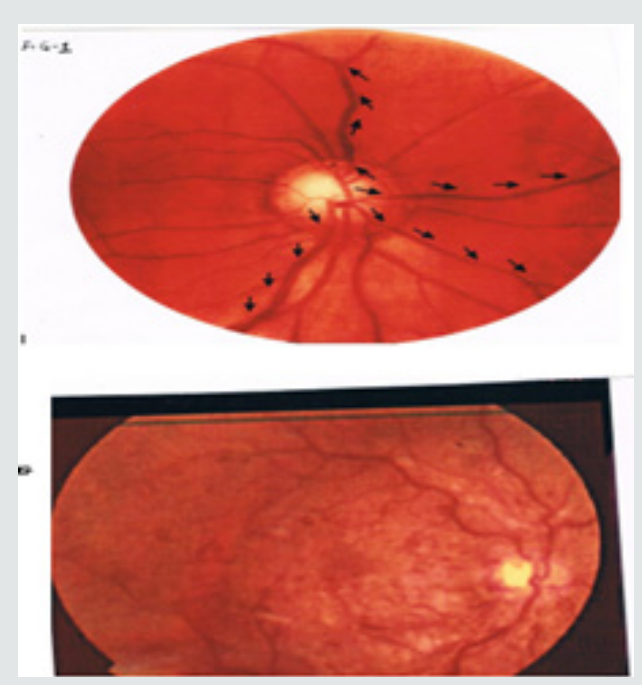

Figure 1: Normal fundus photograph. Arrows showing the technique of Yag laser bursts.

\section{Observation}

They were recorded in (Table1).

Table 1: Visual outcome in 10 eyes of the 10 patients treated with Yag Laser Clot Blast Therapy.

\begin{tabular}{|c|c|c|c|c|c|c|c|c|c|c|c|c|c|}
\hline \multirow{2}{*}{ Cases } & \multirow{2}{*}{$\begin{array}{l}\text { Age } \\
\& \text { Sex }\end{array}$} & \multirow{2}{*}{$\begin{array}{c}\text { Associated } \\
\text { Genral } \\
\text { Diseases }\end{array}$} & \multirow{2}{*}{$\begin{array}{c}\text { Presentation } \\
\text { Time }\end{array}$} & \multirow{2}{*}{ Pre- V.A. } & \multicolumn{9}{|c|}{ Post Laser Visual Acuity } \\
\hline & & & & & $\begin{array}{l}2^{\text {nd }} \\
\text { Day }\end{array}$ & $\begin{array}{c}1^{\text {st }} \\
\text { week }\end{array}$ & $3^{\text {rd Week }}$ & $\begin{array}{c}6^{\text {th }} \\
\text { Week }\end{array}$ & $\begin{array}{c}12^{\text {th }} \\
\text { Week }\end{array}$ & $\begin{array}{c}2^{\text {th }} \\
\text { Week }\end{array}$ & $\begin{array}{c}48^{\text {th }} \\
\text { Week }\end{array}$ & 2 Years & 3 Years \\
\hline 1 & 24 & $\begin{array}{l}\text { Hyperten- } \\
\text { sion }\end{array}$ & 1 month & F.C. & 0.3 & 0.4 & 0.5 & 0.5 & 0.6 & 0.6 & 0.6 & 0.6 & 0.6 \\
\hline 2 & 57 & Diabetic & 1.5 month & F.C. & 0.4 & 0.5 & 0.6 & 0.7 & 0.8 & 0.8 & 0.8 & 0.8 & 0.8 \\
\hline 3 & 46 & Normal & 1 month & F.C. & 0.3 & 0.4 & 0.5 & 0.5 & 0.6 & 0.6 & 0.6 & 0.6 & 0.6 \\
\hline 4 & 58 & Normal & 1.5 month & F.C. & 0.4 & 0.5 & 0.6 & 0.7 & 0.8 & 0.8 & 0.8 & 0.8 & 0.8 \\
\hline 5 & 51 & Normal & 1 month & F.C. & 0.3 & 0.4 & 0.5 & 0.5 & 0.6 & 0.6 & 0.6 & 0.6 & 0.6 \\
\hline 6 & 49 & Normal & 1.5 month & F.C. & 0.4 & 0.5 & 0.6 & 0.7 & 0.8 & 0.8 & 0.8 & 0.8 & 0.8 \\
\hline 7 & 50 & Normal & 1 month & F.C. & 0.3 & 0.4 & 0.5 & 0.5 & 0.6 & 0.6 & 0.6 & 0.6 & 0.6 \\
\hline 8 & 55 & Normal & 1.5 month & F.C. & 0.4 & 0.5 & 0.6 & 0.7 & 0.8 & 0.8 & 0.8 & 0.8 & 0.8 \\
\hline 9 & 62 & Normal & 1 month & F.C. & 0.3 & 0.4 & 0.5 & 0.5 & 0.6 & 0.6 & 0.6 & 0.6 & 0.6 \\
\hline 10 & 64 & Normal & 1.5 month & F.C. & 0.4 & 0.5 & 0.6 & 0.7 & 0.8 & 0.8 & 0.8 & 0.8 & 0.8 \\
\hline \multicolumn{14}{|c|}{ Pre $=$ Pre-treatment } \\
\hline
\end{tabular}
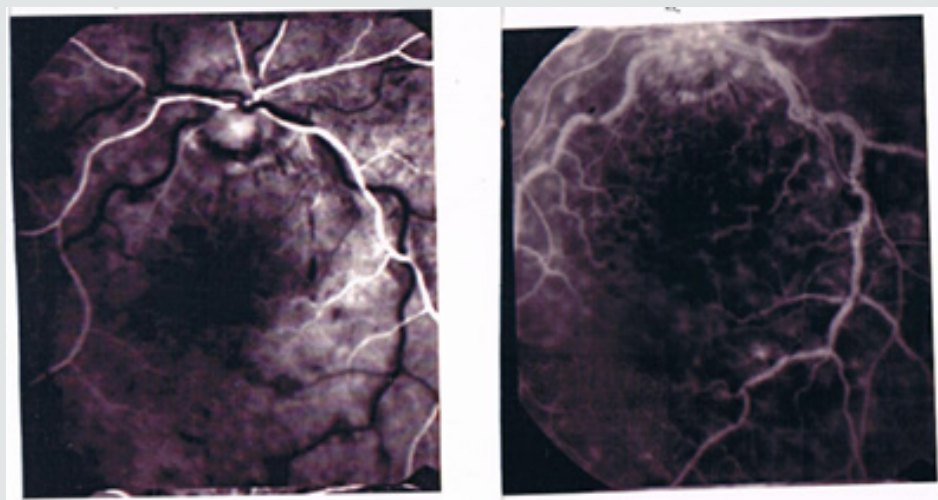

Figure 2: Normal fundus photograph. Arrows showing the technique of Yag laser bursts. 

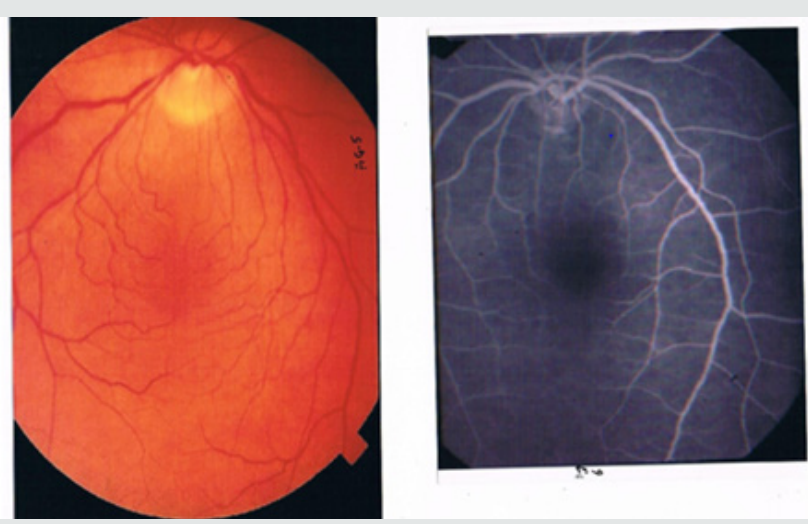

Figure 3: Pre-treatment fluorescein angiogram showing blocked.

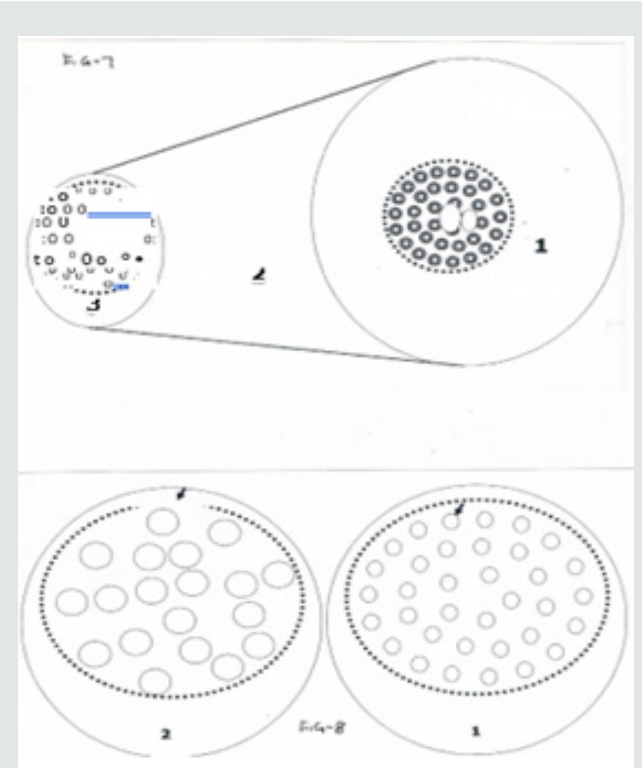

Figure 4: Post treatment fluorescein angiogram showing resolution of fundus lesions and absent macular edema.

a) Visual Acuity: - It improved to $0.4(20 / 50)$ in the first week of the treatment in all the 10 cases. The improvement in visual acuity in subsequent weeks was 0.1 per week till 5th week. Final improvement in visual acuity to $0.8(20 / 25)$ was seen in 6 cases; to $0.7(20 / 30)$ in 2 cases and $0.6(20 / 33)$ in 1 case and $0.5(20 / 40)$ in one case. This visual acuity was maintained till a follow up of 2-4 years [3].

b) Resolution of Fundus Lesions: - The typical fundus picture of the cases is given which showed dilatation of the affected vein and venules with hemorrhages and macular edema in all the cases (Figure 2). The pre-treatment fluorescein angiography showed leakage of dye on the optic disc, in areas along the course of vein (Figure 3) and after the treatment, it showed restoration of blood flow with decrease in size of the venules, veins and absence of macular edema (Figure 4). The lesions started resolving after the day of treatment and completely resolved in 4-6 weeks (5 weeks).

c) Complication: - No complications had occurred till date [4]. There was no development of neo-vascularization in the retina, or in the angle of the anterior chamber. No case had developed thrombotic glaucoma.

\section{Discussion}

The idea of blasting of the dotted blood in the blocked central retinal vein struck to me from the use of Yag laser in removing the pigment dust from the surfaces of some implanted intra-ocular lenses. It was noticed that if we kept the settings of slit lamp at 125 micron anterior and gave a burst of 1-1.5milli Joules, the dust got detached on a wider area of the implanted intra-ocular lens without damaging the lens $[5,6]$. This analogy was applied in this study on 2 blind eyes that showed complete safety of this modality, as there were no complications in the follow up, which further confirmed our idea to use it for this purpose. In this study, 10 cases were studied by this technique. Review of the literature showed that the initial improvement of the visual acuity with other procedures took about 1-4 months5:7'5 as a result the improvement seen after their procedures could not be definitely said to result from the intervention only [7]. The visual acuity of the patients was finger counting at 1 meter distance prior to the treatment. However, in the 
laser clot blast therapy, the visual acuity improved to $0.4(20 / 50)$ on 2nd day, which was clear cut proof of the beneficial effect of the technique. It appeared that the Yag laser energy had disintegrated the clotted blood in the blocked vein without damaging the vein or the adjacent retinal tissue. Some authors preferred to wait till complications of central retinal vein block started appearing. In our opinion, it was not correct but an absurd approach as the damage was bound to occur with uncertain outcome. Our study revealed that by opening of the flow in the blocked central vein at the earliest, not only improved the visual results but also shortened the recovery period with no subsequent complications. The treatment in the form of laser clot therapy should be carried out irrespective of the type of central retinal vein block. It should be carried out as an urgent outdoor procedure irrespective of the age, sex or associated disease. In the branch vein study groups, the final vision in laser treated eye improved to $20 / 40$ to $20 / 50$, compared with $20 / 70$ in untreated eyes. Nevertheless, the treatment effect was negligible when the initial vision was in the poorer range of the $20 / 40$ to $20 / 200$ as inclusions criterion $[8,9]$. The treatment in the form of photocoagulation1 is destructive and is aimed to treat cases who develop neovascularization or non-resolving macular edema and not as an effort to correct the main problem of venous occlusion. The other surgical procedures in form of chorioretinal anastomosis, advential sheathotomy 678 and cannulation ${ }^{\circ}$ although seem logical but are potentially hazardous with indefinite outcome. The purpose of our investigation was an attempt to correct what we believed to be the pathogenic mechanism in central retinal vein occlusion. We tried to lyse the clotted blood or other intra-vascular factors, which had in our opinion, lead on to the stasis of venous blood [10]. This therapy proved useful as it improved the blood flow and abolished the occurrence of complications, which usually occur in this condition.

\section{References}

1. Kohner EM, Laatikainen Leila, James Oughton (1983) The Management of Central Retinal Vein Occlusion. Ophthalmology 90484-90487.

2. Kohner EM, Petit JE, Hamilton AM (1976) Streptokinase in Central Venous Retinal Vein Occlusion: a controlled clinical trial. Brit Med J 1: 550-553.

3. Kohner EM, Barnes AJ, Hill DW (1979) Effect of Viscosity on Retinal Blood Flow, Effects of! so-volumetric Haemodilution, concilluim ophthalmologicum. Kyoto 1: 826-829.

4. Hayreh SS (1975) Treatment of Venous stasis Retinopathy, A preliminary report. Doc Ophthalmol Proc Ser 5: 163-176.

5. Argon laser photocoagulation for macular edema in branch vein occlusion. The Branch vein occlusion study group. Am J Ophthalmol (1984) 98: 271-282.

6. Osterloh MD, Charles S (1988) Surgical decompression of branch retinal vein occlusion. Arch Ophth 126: 1469-1471.

7. Opremeak EM, Bruce RA (1999) Surgical decompression of branch Retinal vein occlusion via anterior venous crossing sheathotomy: a prospective review of 15 cases. Retina 19: 1-5.

8. Shah GK, Sharma S, Fineman MS, Federman J, Brown MM, et al. (2000) Arteriovenous Adventitial Sheathotomy for the treatment of Macular Edema Associated with Branch Retinal Vein Occlusion. Am J Ophthalmol 129: 104-106.

9. McAllister Ian L (2001) Chorio Retinal Venous Anastomosis for Central Venous occlusion. Symposium 13th Congress. European Society of Ophthalmology pp.35.

10. J Weiss, Jeffrey N (2001) Central Retinal Vein Cannulation Am. Acad of Ophth pp.64.

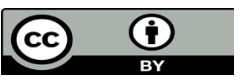

This work is licensed under Creative Commons Attribution 4.0 License

To Submit Your Article Click Here:

Submit Article

DOI: $10.32474 /$ TOOAJ.2019.02.000142

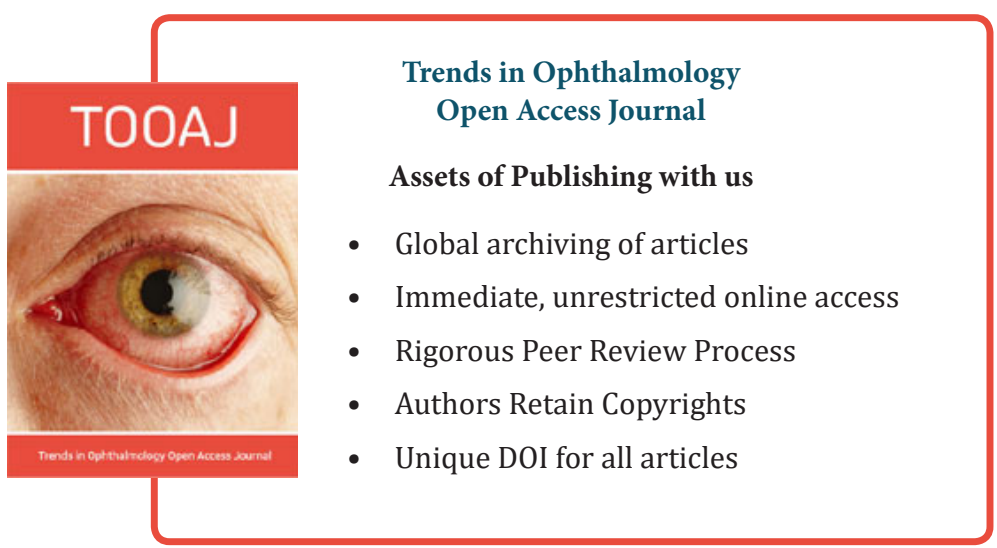

